\title{
A Importância da Identificação do Perfil Epigenético de Metiltransferases de Proteínas para a Detecção e Prognóstico de Leucemias Linfóides Agudas
}

\section{The Importance of Identifying the Epigenetic Profile of Protein Methyltransferases for the Detection and Prognosis of Acute Lymphoid Leukemias}

Murilo Tavares Amorim ${ }^{1 *}$, Célio Amoêdo de $\mathrm{Melo}^{2}$, Shirley Barata Barros ${ }^{3}$, Michele Amaral da Silveira $^{2}$

\section{RESUMO}

Objetivo: Investigar as repercussões biológicas dos efetores de metilação proteica como alternativa para a detecção e prognóstico das Leucemias Linfoides Agudas (LLA). Métodos: Trata-se de uma pesquisa bibliográfica, do tipo integrativa. Possui um desenho observacional, transversal e de vertente qualitativa, com o enfoque de abordar aspectos referentes à epigenética do câncer e o papel de metiltransferases como efetores de metilação proteica para a detecção e prognóstico das leucemias linfoides agudas. Resultados e Discussão: Obteve-se 8 pesquisas que atendiam os critérios pré-determinados para análise e apresentação do seu conteúdo. Foi atribuída a vertente de busca com base na proposta do tema, que teve como função delimitar as formas de apresentação dos estudos. Os estudos tratam da importância do desenvolvimento de moduladores epigenéticos envolvidos na etiologia da doença, bem como na diferenciação, classificação e prognóstico. Conclusão: O presente estudo pôde corroborar para uma compreensão geral acerca da etiologia da LLA, bem como, fornecer insights sobre a identificação de alvos terapêuticos para o prognóstico dessa doença.

Palavras Chave: Câncer; Epigenética; Expressão Gênica; Leucemia Linfóide Aguda da Infância; Metiltransferases de Proteínas; Proliferação Celular.

\section{ABSTRACT}

Objective: To investigate the biological effects of protein methylation effectors as an alternative for the detection and prognosis of Acute Lymphoid Leukemia (ALL). Methods: This is an integrative bibliographic research. It has an observational, cross-sectional and qualitative design, with a focus on addressing aspects related to cancer epigenetics and the role of methyltransferases as protein methylation effectors for the detection and prognosis of acute lymphoid leukemia. Results and Discussion: 8 surveys were obtained that met the predetermined criteria for analysis and presentation of its content. The search aspect was assigned based on the proposal of the theme, which had the function of delimiting the forms of presentation of the studies. The studies address the importance of developing epigenetic modulators involved in the etiology of the disease, as well as in its differentiation, classification and prognosis.

\footnotetext{
${ }^{1}$ Uniiversidade Federal do Pará

*E-mail: muriloamorimbio@gmail.com

${ }^{2}$ Centro Universitário Fibra

${ }^{3}$ Faculdade Cosmopolita
} 
Conclusion: The present study could support a general understanding of the etiology of ALL, as well as provide insights on the identification of therapeutic targets for the prognosis of this disease.

Keywords: Cancer; Epigenetics; Gene expression; Childhood Acute Lymphoid Leukemia; Protein Methyltransferases; Cell Proliferation.

\section{INTRODUÇÃO}

As Leucemias podem ser caracterizadas como neoplasias de origem mesenquimal, predominantemente classificadas segundo a maturação celular, podendo ser designada como aguda; caso haja predomínio de células blásticas, ou crônicas; caso ocorra predomínio de células maduras. Outra forma de ser classificada é a partir da linhagem afetada, sendo denominada linfocítica; quando as alterações são observadas nos linfócitos $\mathrm{T}$, ou B ou mielocítica; quando altera a série mielóide ${ }^{1,2,3}$. A Leucemia Linfóide Aguda (LLA), apresenta maior acometimento na infância, constituindo o tipo mais comum de câncer. $\mathrm{O}$ pico de inciência geralmente ocorre entre os 2 e 5 anos de idade. Pode ser expressa como uma neoplasia do sistema hematopoiético, sendo observada a partir da expansão clonal maligna de células precursoras linfóides ${ }^{4}$. Quanto às manifestações clínicas, principalmente devido a associação difusa e o compromento da atividade medular, estas apresentam-se de forma indeterminada, podendo ser confundida com diversas doenças e outras alterações fisiológicas, sendo de fundamental importância o prognóstico eficaz da doença, a fim de possibilitar a sua remissão, evitando assim, as chances de recidivas ${ }^{5,6}$.

O diagnóstico das leucemias, de modo geral, fundamenta-se a partir de estudos microscópicos sanguíneos, aplicados com enfoque na linhagem leucocitária, a partir de análise em amostras de sangue, aspirados, biópsia de medula óssea e pesquisa em líquido cefalorraquidiano $^{7,8}$. Os estudos buscam avaliar alguns aspectos predominantes, bem estabelecidos, como critérios na identificação de doenças, como a morfologia, a quantidade celular, as reações citoquímicas e a presença ou ausência de marcadores imunofenotípicos $^{8,9}$. Para o diagnóstico da LLA são realizados - a partir do exame do aspirado de medula óssea - testes de citomorfologia do esfregaço, imunofenotipagem por citometria de fluxo e caracterização citogenética. Diversos marcadores epigenéticos têm sido estudados, a fim de fomentar o rastreio para a identificação da LLA, o que pode inferir no achado de novos alvos moleculares com vistas a facilitar a resposta contra a doença. No entanto, a elaboração e o desenvolvimento desses marcadores, somente serão viabilizados a partir de um conhecimento profundo da biologia celular das células que 
compõe o sistema hematopoiético, bem como a associação com os diversos processos que desencadeiam a leucemogênese ${ }^{10}$.

Sob essa abordagem, destacam-se as metiltransferases de proteínas, que são descritas como enzimas que catalisam a transferência de grupos metil $(\mathrm{CH} 3)$ a partir de um substrato S-adenosil metionina (SAM) para resíduos de arginina ou lisina na porção nucleofílica da cadeia de aminoácidos. A metilação pode ser mais bem esclarecida como uma modificação pós-traducional de proteínas, sido amplamente estudada em histonas $^{11,12}$. Como base primordial para o desencadeamento de atividades desreguladoras, destaca-se o nucleossomo, unidade básica da cromatina. Sabe-se portanto, quanto às modificações covalentes, que estas ocorrem em resíduos de lisinas e/ou argininas das extremidades N-terminal das histonas $\mathrm{H} 3$ e $\mathrm{H} 4$ e podem estar potencialmente envolvidas de modo direto, na reparação e no controle da expressão gênica por meio do remodelamento da cromatina em diversas doenças associadas à carcinogênese ${ }^{13}$.

Quanto à metilação das histonas, cada um dos seus resíduos de aminoácidos pode receber um ou dois grupamentos metil. Especificamente no caso de lisinas, é possível, ainda, a adição de um terceiro grupo metil. No mais, algumas modificações podem também ocorrer em um único resíduo das histonas ou simultaneamente em múltiplos aminoácidos. Desse modo, a atividade de histona metiltransferase em resíduos de lisina e arginina é catalisada a partir de uma família de enzimas com um domínio catalítico conservado denominado SET (Suppressor of variegation, Enhancer of Zeste, Tritothorax $)^{13,14}$. Portanto, partindo desse pressuposto, diante da repercussão biológica que pode ser desencadeada pelo efeito da metilação de histonas, pode ser observada a compactação da cromatina, impedindo a transcrição, ou descompactação, permitindo-a. Estudos descrevem a relação evidente de modificações pós-traducionais de histonas, causando impacto corrente na dinâmica estrutural dos nucleossomos, afetando o acesso dos fatores de transcrição à fita de $\mathrm{DNA}^{11,15}$. Desse modo, em virtude da dinâmica da metilação das histonas possuir um papel importante em processos fisiológicos do ciclo celular, acredita-se que estas, possam possuir relação direta com genes promotores que ativam respostas reguladoras para atividade de metiltransferase em LLA e possível determinante de prognóstico ${ }^{16}$. 
Em decorrência das evidências abordadas acerca do papel da atividade berrante de metiltransferases proteicas na carcinogênese e determinação prognóstica em diversos tipos de tumores e em face da identificação de genes relacionados à leucemias, nota-se a importância de estudos que viabilizem a pesquisa de metiltransferases de lisinas em LLA. Nessa perspectiva, tendo em vista que este tema trata-se de uma abordagem recente na epigenética, acredita-se que esta revisão possa acrescentar acerca do conhecimento da biologia da LLA, assim como possibilitar a provável relação de genes que codificam proteínas com atividade metiltranferase, causando desregulações associadas ao processo carcinogênico $^{16,17}$. Desse modo, o presente estudo visa investigar as repercussões biológicas dos efetores de metilação proteica como alternativa para a detecção e prognóstico das leucemias linfoides agudas.

\section{MÉTODOS}

O estudo desenha-se como uma pesquisa observacional, transversal e de vertente qualitativa. Trata-se de uma pesquisa bibliográfica, do tipo integrativa, acerca de aspectos referentes à epigenética do câncer e o papel de metiltransferases como efetores de metilação proteica para a detecção e prognóstico das leucemias linfoides agudas. A fim de esclarecer os critérios que foram estabelecidos e precederam à execução da busca, se viu necessário delinear a construção de uma perspectiva de enfoque baseado em um delineamento prospectivo, descrita a seguir.

As bases de dados selecionadas para o levantamento bibliográfico do estudo, foram as plataformas de busca: Medical Literature Analysis and Retrieval System Online (Medline), Cochrane, Scientific Eletronic Library Online (SciELO) e Literatura LatinoAmericana e do Caribe em Ciências da Saúde (LILACS). Somente foram selecionados artigos inéditos, publicados nos idiomas português, inglês e espanhol. As palavras-chave utilizadas para triagem e busca dos artigos foram: Câncer, Epigenética, Expressão Gênica, Leucemia Linfóide Aguda da Infância, Metiltransferases de Proteínas e Proliferação Celular.

Afim de selecionar os artigos disponíveis na literatura a partir de uma busca mais específica, foi realizada filtragem nas bases de dados com base no ano de publicação (2017-2021), no tipo de população de estudo e tipo de abordagem metodológica. Foi atribuída prioridade significativa aos estudos que apresentaram uma proposta de inovação na área. Foram utilizados somente estudos disponíveis na íntegra; indexados nas bases de 
dados; publicados em revistas de alto impacto e disponíveis nos idiomas português, inglês e espanhol. Foram selecionados para compor o estudo, somente pesquisas com enfoque na aplicação de metiltransferases como possível alternativa para prognóstico da LLA.

Ao longo do processo de busca e obtenção dos dados que seriam utilizados como subsídio para a construção do produto final, foram definidos, a partir dos parâmetros de utilidade, as variáveis metodológicas qualitativas que iriam compor a estrutura pertencente à fundamentação teórica dos dados obtidos, a fim de retratar de uma forma coesa e objetiva, a caracterização dos determinantes mais importantes encontrados nos estudos. Buscou-se avaliar os títulos e os descritores, sob critério independente aos resumos. Depois, dentre os estudos selecionados para análise posterior, os resumos eram verificados, seguido da análise do texto na íntegra e estes, apresentando resultados relevantes à proposta enquadrada nas linhas temáticas previamente determinadas com base nas vertentes qualitativas de busca, foram registradas, selecionadas e demonstradas em quadros, para melhor compreensão.

\section{RESULTADOS E DISCUSSÃO}

Após a realização de uma busca sistematizada e registro dos estudos selecionados, obteve-se 8 pesquisas que atendiam os critérios pré-determinados para análise e apresentação do seu conteúdo. Foi atribuída a vertente de busca com base na proposta do tema, que teve como função delimitar as formas de apresentação dos estudos, sendo esta: Perfil de Metiltransferases de Proteínas, expressão e silenciamento de genes em Leucemias Linfóides Agudas e doenças associadas. Sendo apresentados em quadros, contendo Autores e Ano de Publicação; Periódico; Título do Estudo; Síntese e Objetivos; Contribuições e Conclusões. O quadro 1 demonstra os estudos selecionados com enfoque na linha temática proposta. 
Quadro 1: Perfil de Metiltransferases de Proteínas, Expressão, Silenciamento de genes e fatores biológicos relacionados ao prognóstico de Leucemias Linfóides Agudas e Doenças Associadas

\begin{tabular}{|c|c|c|c|c|c|}
\hline$\#$ & Autor/Ano & Periódico & Título & Síntese e Objetivos & Contribuições e Conclusões \\
\hline & $\begin{array}{l}\text { Bergmann, et } \\
\text { al., (2017) }\end{array}$ & $\begin{array}{l}\text { Pediatric Blood } \\
\text { Cancer }\end{array}$ & $\begin{array}{l}\text { DNA methylation profiling of } \\
\text { pediatric B-cell } \\
\text { lymphoblastic leukemia with } \\
\text { KMT2A rearrangement } \\
\text { identifies hypomethylation at } \\
\text { enhancer sites }\end{array}$ & $\begin{array}{l}\text { Os autores traçaram o perfil de metilação } \\
\text { do DNA em Leucemia Linfobçastica } \\
\text { Aguda (LLA) com rearranjo da } \\
\text { metiltransferase } 2^{\mathrm{a}} \text { específica da lisina K } \\
\text { (KMT2Ar) em matriz de células } \\
\text { leucêmicas B precurssoras baseado em } \\
\text { microarray de DNA genômico }\end{array}$ & $\begin{array}{l}\text { Foram identificadas mudanças significativas de metilação do } \\
\text { DNA baseada em KMT2A e LLA em diferentes lócus e } \\
\text { domínios em regiões promotoras do genoma, influenciado } \\
\text { diretamente por translocação. Houveram mudanças na } \\
\text { metilação do DNA em KMT2A e todos os genes } \\
\text { potencializadores rastreados parecem estar envolvidos na } \\
\text { leucemogênese e hematopoiese normal, bem como redes de } \\
\text { fator de transcrição }\end{array}$ \\
\hline 1 & $\begin{array}{l}\text { Pollack, et al., } \\
\text { (2017) }\end{array}$ & $\begin{array}{l}\text { Journal of } \\
\text { Clinical } \\
\text { Oncology }\end{array}$ & $\begin{array}{l}\text { O6-Methylguanine-DNA } \\
\text { Methyltransfer. Expression } \\
\text { Strongly Correlates With } \\
\text { Outcome in Childhood } \\
\text { Malignant Gliomas: Results } \\
\text { From the CCG-945 Cohort }\end{array}$ & $\begin{array}{l}\text { No presente estudo foi desenvolvida } \\
\text { uma associação entre a expressão de } \\
\text { O6-metilguanina-DNA metiltransferase } \\
\text { (MGMT) e a duração da sobrevida em } \\
\text { crianças, a partir da utilização de } \\
\text { amostras de tumor. Os autores puderam } \\
\text { observar uma associação entre a } \\
\text { superexpressão de MGMT e o parâmetro } \\
\text { adverso permaneceu significativamente } \\
\text { elevado após a estratificação para } \\
\text { diagnóstico histológico institucional, } \\
\text { idade, quantidade de tumor residual e } \\
\text { localização }\end{array}$ & $\begin{array}{l}\text { O estudo pôde demonstrar uma expressão significativamente } \\
\text { elevada de MGMT em gliomas malignos da infância, além de } \\
\text { uma forte associação com resultado potencialmente adverso em } \\
\text { crianças tratadas com quimioterapia baseada em alquilador, } \\
\text { independente dos fatores relacionados aos prognósticos } \\
\text { clínicos. Os achados puderam indicar que o MGMT pode ser } \\
\text { considerado um marcador para prognóstico de fundamental } \\
\text { importância em gliomas malignos pediátricos. Portanto, de } \\
\text { modo geral, a fim de dar seguimento à pesquisa, os autores } \\
\text { tratam da necessidade de validar os achados em uma coorte } \\
\text { independente antes de implementar a estratificação terapêutica } \\
\text { com base no status de expressão de MGMT }\end{array}$ \\
\hline 2 & $\begin{array}{l}\text { Navarrete- } \\
\text { Meneses, et al., } \\
\text { (2017) }\end{array}$ & $\begin{array}{l}\text { BMHIM } \\
\text { Journal }\end{array}$ & $\begin{array}{l}\text { Epigenetic alterations in } \\
\text { acute lymphoblastic leukemia }\end{array}$ & $\begin{array}{l}\text { Os autores abordam como a regulação } \\
\text { epigenética por meio da metilação do } \\
\text { DNA, modificação de histonas e por } \\
\text { microRNAs podem desempenhar um } \\
\text { papel no desenvolvimento e evolução da } \\
\text { LLA e outros tipos de câncer. Os autores } \\
\text { destacam que pesquisas contínuas nessa } \\
\text { área poderão oferecer diversas } \\
\text { informações que permitirão um melhor } \\
\text { entendimento da complexa etiologia da } \\
\text { LLA }\end{array}$ & $\begin{array}{l}\text { Os autores buscam viabilizar uma pesquisa com ênfase na } \\
\text { LLA, abordando uma proposta acerca de como os níveis de } \\
\text { regulação em diferentes mecanismos moleculares podem estar } \\
\text { envolvidos na etiologia da doença e no diagnóstico, na } \\
\text { classificação e no prognóstico dos pacientes. Os autores trazem } \\
\text { uma nova perspectiva acerca do advento dos estudos que tratam } \\
\text { da associação do genoma e detecção de modificações } \\
\text { epigenéticas características da LLA, promovendo um } \\
\text { delineamento multifatorial continuado acerca da importância da } \\
\text { complexidade e heterogeneidade da regulação epigenética nesta } \\
\text { doença }\end{array}$ \\
\hline 3 & $\begin{array}{l}\text { Rahmani, et al., } \\
\text { (2017) }\end{array}$ & $\begin{array}{l}\text { Biomed. \& } \\
\text { Pharma - } \\
\text { cotherapy }\end{array}$ & $\begin{array}{l}\text { Aberrant DNA methylation of } \\
\text { key genes and Acute } \\
\text { Lymphoblastic Leukemia }\end{array}$ & $\begin{array}{l}\text { Foi realizada uma revisão bibliográfica } \\
\text { sobre a metilação de genes-chave } \\
\text { envolvidos em doenças malignas } \\
\text { hematopoiéticas e sua importância na } \\
\text { patogênese da LLA. Foi demonstrado } \\
\text { que as alterações de metilação do DNA } \\
\text { em regiôes promotoras dos genes podem } \\
\text { desempenhar papéis cruciais na } \\
\text { tumorigênese e também foi relatada } \\
\text { como associada ao prognóstico da } \\
\text { doença }\end{array}$ & $\begin{array}{l}\text { Os autores ressaltam uma temática amplemanete descrita na } \\
\text { literatura, que a metilação do DNA é um mecanismo de suporte } \\
\text { chave na preservação da memória epigenética em células de } \\
\text { mamíferos. Descrevem que diversos genes metilados em } \\
\text { tumores não são expressos em células normais equivalentes. } \\
\text { Abordam que na leucemia, o silenciamento epigenético por } \\
\text { metilação do DNA tem sido descrito em diversas classes de } \\
\text { genes regulatórios, associados à metilação. Porém, os autores } \\
\text { concluem que a se metilação do gene afeta o ganho de função } \\
\text { em ou se é apenas uma assinatura de instabilidade epigenética, } \\
\text { ainda não foi totalmente esclarecida. }\end{array}$ \\
\hline 4 & $\begin{array}{l}\text { Sobiak, et al., } \\
\text { (2018) }\end{array}$ & $\begin{array}{l}\text { Oncology } \\
\text { Letters }\end{array}$ & $\begin{array}{l}\text { Thiopurine methyltransferase } \\
\text { activity in children with acute } \\
\text { myeloid leukemia }\end{array}$ & $\begin{array}{l}\text { O presente estudo se propôs a avaliar os } \\
\text { polimorfismos genéticos e a atividade da } \\
\text { Tiopurina Metiltransferase (TPMT) em } \\
\text { crianças com LMA em diferentes } \\
\text { estágios de tratamento e comparação dos } \\
\text { resultados com os obtidos em crianças } \\
\text { com LLA. Foi feito um estudo } \\
\text { descritivo, baseado nos dados dos } \\
\text { pacientes, e de acordo com a verificação } \\
\text { das medianas das atividades de TPMT } \\
\text { nas crianças com LMA e LLA }\end{array}$ & $\begin{array}{l}\text { Os resultados preliminares obtidos nesse estudo, demonstram } \\
\text { que a atividade de TPMT na LMA pode ser aumentada em } \\
\text { comparação com a da LLA. Os autores retratam a necessidade } \\
\text { de estudos mais abrangentes sobre a associação entre o } \\
\text { metabolismo da tiopurina e o resultado do tratamento na } \\
\text { Leucemia Mielóide Aguda., foi detectado um aumento quando } \\
\text { comparadas com as medianas de atividades TPMT em crianças } \\
\text { com LLA. Após análise basedas nas medianas dos resultados } \\
\text { obtidos das amostras dos pacientes, os resultados puderam } \\
\text { indicar, de modo geral, que a atividade de TPMT na LMA pode } \\
\text { ser aumentada em comparação com a da LLA }\end{array}$ \\
\hline 5 & $\begin{array}{l}\text { Meyer, et al., } \\
\text { (2019) }\end{array}$ & $\begin{array}{l}\text { Cancer Drug } \\
\text { Resistance }\end{array}$ & $\begin{array}{l}\text { The epigenome in pediatric } \\
\text { acute lymphoblastic } \\
\text { leukemia: drug resistance } \\
\text { and therapeutic opportunities }\end{array}$ & $\begin{array}{l}\text { Este artigo de revisão se concentra em } \\
\text { descrever o papel do epigenoma na } \\
\text { patogênese, progressão e resposta à } \\
\text { terapia da LLA, além de destacar a } \\
\text { importância dos esforços pré-clínicos e } \\
\text { clínicos para direcionamento do } \\
\text { epigenoma como um meio de viabilizar } \\
\text { o prognóstico para crianças com LLA e } \\
\text { outros canceres com etiologia } \\
\text { semelhante }\end{array}$ & $\begin{array}{l}\text { Apesar dos resultados obtidos na pesquisa desenvolvida pelos } \\
\text { autores, é descrita a importância de mais estudos, sob diferentes } \\
\text { abordagens, a fim de compreender a relação causal entre tais } \\
\text { anormalidades epigenéticas e a leucemogênese. Diversos } \\
\text { estudos se concentram em reverter esse estado epigenético } \\
\text { alterado no contexto da recidiva da doença, a fim de restaurar a } \\
\text { quimiossensibilidade e induzir remissões e desse modo, } \\
\text { contribuir para a diferenciação na sensibilidade à quimioterapia }\end{array}$ \\
\hline 6 & $\begin{array}{l}\text { Bellamy, et al., } \\
2020\end{array}$ & $\begin{array}{l}\text { Frontiers in } \\
\text { Oncol. }\end{array}$ & $\begin{array}{l}\text { Increased Efficacy of Histone } \\
\text { Methyltransferase G9a } \\
\text { Inhibitors Against MYCN- } \\
\text { Amplified Neuroblastoma }\end{array}$ & $\begin{array}{l}\text { Neste estudo, foi avaliada uma expressão } \\
\text { da proténa G9a em relação aos fatores } \\
\text { estratificantes em Neuroblastoma (NB) e } \\
\text { também avaliados três inibidores de } \\
\text { G9a. Com base nos achados, foi } \\
\text { proposto que a inibição farmacêutica de } \\
\text { G9a é uma abordagem terapêutica } \\
\text { viável, especialmente para NB } \\
\text { impulsionado por amplificação MYCN, } \\
\text { um driver conhecido de outros tipos de } \\
\text { câncer e doenças associadas }\end{array}$ & $\begin{array}{l}\text { No presente artigo, foi destacada uma vulnerabilidade } \\
\text { terapêutica que anteriormente ainda não tinha sido reconhecida } \\
\text { em neuroblastomas com amplificação de MYCN para } \\
\text { inibidores de G9a. Os autores buscam enfatizar sobre a } \\
\text { necessidade de trabalhos futuros sobre esses cânceres com } \\
\text { inibidores atualmente estudados, de modo a viablizar o } \\
\text { desenvolvimento de inibidores de G9a de próxima geração. } \\
\text { Desse modo, a pesquisa também se propõe a racionalizar o } \\
\text { direcionamento farmacológico combinado de G9a e a EZH2 } \\
\text { para neuroblastoma no futuro, visto sua participação na } \\
\text { metilação da histona e na repressão transcricional }\end{array}$ \\
\hline 7 & $\begin{array}{l}\text { Zhang, et al., } \\
\text { (2020) }\end{array}$ & Cancers & $\begin{array}{l}\text { DNA Methyltransf. in } \\
\text { Cancer: Biology, Paradox, } \\
\text { Aberrations, and Targeted } \\
\text { Therapy }\end{array}$ & $\begin{array}{l}\text { A revisão tem por função apresentar } \\
\text { algumas das características biológicas e } \\
\text { funcionais dos DNA's Metiltransferase } \\
\text { (DNMTs), suas alterações em diferentes } \\
\text { doenças malignas e as terapias que os } \\
\text { direcionam. Desse modo, os autores } \\
\text { propuseram mais ideias para direcionar } \\
\text { os DNMTs, o que pode fornecer a base } \\
\text { para futuros tratamentos de câncer }\end{array}$ & $\begin{array}{l}\text { O estudo se propôs a introduzir algumas das características dos } \\
\text { DNMTs, bem como do DNMT3A e diversos outros papéis dos } \\
\text { DNMTs nos cânceres e as estratégias que estão disponíveis } \\
\text { para direcionar os DNMTs na terapia do câncer. Também } \\
\text { puderam propôr uma nova perspectiva, antes não abordada para } \\
\text { o tratamento de cânceres múltiplos. Os autores concluem que, } \\
\text { no momento, em virtude da escassez de estudos, ainda não é } \\
\text { adequado usar inibidores DNMT para tratar os cânceres, e as } \\
\text { terapias para esse tipo de câncer precisam ser mais exploradas. }\end{array}$ \\
\hline
\end{tabular}

Fonte: Autoria Própria 
De acordo com o que foi exposto anteriormente, sabe-se que a inibição direcionada de proteínas responsáveis por modular alterações epigenéticas trata-se de uma prioridade cada vez mais significativa na resposta terapêutica contra o câncer, e diversos inibidores moleculares tem sido desenvolvidos a fim de promover a redução ou inativação desses mediadores. Tratando-se de doenças com etiologia semelhantes à proposta de estudo, o Neuroblastoma (NB), um tumor sólido pediátrico com poucas mutações intragênicas, em estudo desenvolvido por Bellamy, et al., (2020) ${ }^{18}$, foi feita uma associação com a desregulação epigenética da Metiltransferase G9a/EHMT2. Nesse estudo, os autores propuseram validar a Histona Metiltranferase (HM) associada a indicadores de prognósticos ruins em Recém Nascidos (RN). Foram obtidos altos níveis de expressão em linhagem celulares de NB a partir de estudo de amplificação MYCN, que é um teste amplamente utilizado e classificado como o principal determinante em desfechos de propensão ruim em pacientes RN. Posteriormente, foi demonstrado que a proteína G9a em tumores primários é muito expressa em níveis elevados de NB com pouca diferenciação ou indiferenciados e se correlacionam com uma alta expressão de EZH2, que é uma oncoproteína muito estudada em NB. Portanto, o estudo apresentou um importante papel, ainda pouco estudado, de G9a no RN, em tumores amplificados por MYCN.

O maior estudo randomizado para gliomas malignos infantis concluido até o presente momento, realizado por Pollack, et al., $(2021)^{19}$, examinaram a associação entre expressão de O2-Metilguanina-DNA-Metiltransferase (MGMT), constituída como um mecanismo proximal para resistência ao alquilador, já que promove a transferência de grupos alquil da posição O6 de nucleotídeos de guanina do DNA para um sítio aceitador de grupos alquil dentro de MGMT. Esse estudo apresenta significativa importância, uma vez que, como demonstrado por Bellamy, et al., (2020) ${ }^{18}$, também é apresentada a desregulação epigenética de MT em diversos tipos de câncer e deve-se estabelecer se existe uma relação em gliomas malignos pediátricos, já que a maioria das crianças recebe esses agentes como parte da sua terapia inicial. Os achados indicaram que o MGMT tratase de um marcador prognótico importante em gliomas malignos pediátricos, entretanto, estudos moleculares são necessários a fim de prover avaliações prospectivas de terapias adjuvantes.

Com mais enfoque na proposta temática do presente estudo, Sobiak, et al., $(2018)^{20}$ realizaram em seu estudo, uma avaliação dos polimorfismos genéticos e 
atividade da enzima tiopurina metiltransferase, responsável por determinar o efeito antileucêmico das tiopurinas usadas na quimioterapia da LLA e da LMA. Os autores puderam verificar, em concordância com o que já está exposto nos estudos descritos, uma relação da atividade da metiltransferase em pacientes com LMA em comparação com os pacientes com LLA. Porém, são necessários estudos citogenéticos e moleculares adicionais acerca do metabolismo da tiopurina na LMA. Em concordância com os dados apresentados, em estudo desenvolvido por Zhang, et al., $(2020)^{21}$, os autores abordam sobre como as funções aberrantes das DNA's metiltransferases estão associadas à tumorigênese. A abordagem do estudo busca descrever a importância desses estudos moleculares adicionais para a compreensão da malignidade dos tumores e fatores associados ao tumor, como a instabilidade genômica e a ativação de genes supressores hipermetilados, que pioram o diagnótico e dificultam o tratamento dos pacientes. No entanto, apesar desses aspectos, o impacto dos DNMT's ainda precisa ser mais discutido e explorado.

Como descrito anteriormente, a metilação do DNA é exposta como um processo dinâmico responsável por influenciar de forma direta na expressão gênica, de modo a alterar os lócus codificadores ou não codificadores. Apesar dos estudos frequentes quanto à epigenética da LLA, a recidiva ainda é constante em uma porção significativa dos pacientes acometidos. Portanto, vem se tornado fundamental a compreensão dos fatores epigenéticos como mecanismos na patogênese das neoplasisas e podem ser considerados excelentes alvos da terapia e do prognóstico da doença. Em estudo desenvolvido por Rahmani, et al., $(2017)^{22}$, os autores revisaram o perfil de metilação de genes envolvidos em doenças malignas hematopoiéticas na patogênese da LLA, como alternativa de prognóstico da doença, a partir do rastreio da inativação desses genes. Os autores puderam determinar o silenciamento epigenético pela metilação do DNA em genes relacionados à inibidores de quinase dependente de ciclina, genes de reparo de DNA, moderadores de apoptose, receptores nucleares, fatores de transcrição e moléculas de adesão celular. Nesse contexto, o quadro 2 demonstra a classificação dos genes mais afetados por modificações epigenéticas na LLA, segundo sua função biológica. 
Quadro 2: Classificação dos genes mais afetados em LLA e função biológica

\begin{tabular}{|c|c|c|c|}
\hline$\#$ & Proliferação & Apoptose & Transcrição \\
\hline Genes & CDKN1A & TP73, DAPK1 & HDAC1, HDAC3, \\
Codificadores de & CDKN1C & BNIP3, PPP1 & HDAC4, HDAC6 \\
Metilstransferases & CDKN2A & R13B, APC & HDAC7, HDAC8 \\
de Proteínas & CDKN2B & EPHA2, RASSF1 & HDAC9, PROP1 \\
& CDK6MCTS1 & PTEN, APAF1 & TAF3, H2AFA4 \\
& DGKG & DBC1, DDC, & ELF5, ZBTB16 \\
& DBC1 & ERBB4 & CNOT1, \\
& ABL1 & EPHA2, EYA2 & TADA2A \\
& mRNA34, & GATA4, \\
& mRNA34C & HLFTCF3 \\
& & NOXA, PTPN6 & FOXF2, PAX2 \\
& & RASSF6, SFRP1 & PAX5, PAX6 \\
& WDR35, PAR4 & TFAP2A, \\
& & & TWIST72 \\
& & & TP73, HOXA4 \\
& & & ESR1, MYOD1 \\
& & & \\
& & &
\end{tabular}

Fonte: Rahmani, et al., (2017); Zhang, et al., (2020); Meyer, et al., (2019); Navarrete-Meneses, et al.,

(2018)

Em conformidade com os produtos expostos, as alterações epigenéticas destacamse como um importante contribuinte para a oncogênese e como cooperam com as mutações genéticas para conduzir os níveis de expressão gênica em células cancerosas. Em virtude disso, o padrão de metilação deve ser continuamente observado a fim de observar mudanças e fomentar a utilização de alternativas viáveis para o desenvolvimento de biomarcadores para pacientes pediátricos, além de terapias alvos como controle da leucemogênese, conforme descrito por Bergmann, et al., (2017). Esse rastreio pode ocorrer a partir da identificação dos genes e dos mecanismos epigenéticos de resposta contra a doença. Nesse contexto, segundo Meyer, et al., (2019) ${ }^{23}$ e Navarrete-Meneses, et al., $(2018)^{24}$, o epigenoma destaca-se como um importante mediador da recidiva da LLA, revelando padrões específicos de aberrações correlacionadas à expressão gênica. Os estudos trazem os genes mais expressos e tem por função tratar acerca do desenvolvimento de moduladores epigenético nesse contexto, estão diretamente envolvidos na etiologia da doença, bem como no diagnóstico, classificação e prognóstico dos pacientes.

\section{CONCLUSÃO}

A regulação epigenética por meio da metilação do DNA, alterações de histonas e atividade de metiltransferases, desempenha um papel de fundamental importância na relação com o desenvolvimento e evolução da LLA e outros tipos de câncer. O advento 
dos estudos que compreendam a associação do genoma com a detecção das modificações epigenéticas da LLA, deve ser amplamente pesquisado, visto a complexidade e a heterogeneidade da regulação epigenômica, característica desse tipo de doença. O presente estudo pôde corroborar para uma compreensão geral acerca da etiologia da LLA, bem como, fornecer insights sobre a identificação de alvos terapêuticos para o prognóstico dessa doença.

\section{REFERÊNCIAS}

[1] ALMEIDA, T.J.B. Avanços e perspectivas para o diagnóstico da leucemia linfoide aguda. Candombá, Revista virutal, v.5, n.1, p.40-55, 2009.

[2] SILVEIRA, N.A. ARRAES, S.M.A.A. A imunofenotipagem no diagnóstico diferencial das leucemias agudas: uma revisão. Arq Mudi. v.12, n.1, p.5-14, 2008.

[3] FADEL, A.P. Investigação laboratorial de LLA. Ac\&T Científica, v. 1, n. 2, 2010.

[4] FARIAS, M. G., De CASTRO, S. M. Diagnóstico laboratorial das leucemias linfoides agudas. J. Bras. Patol. Med. Lab. v.40, n.2, p.91-8, abril 2004.

[5] PUI, C. H., W. L, et al. Biology, risk stratification, and therapy of pediatric acute leukemias: an update." J Clin Oncol, v. 29, n. 5, p. 551-565, 2011.

[6] MARGOLIN, J. F., C. P, et al. Acute Lymphoblastic Leukemia. Principles and Practice of Pediatric Oncology. p. 538-590, 2006.

[7] ONCIU, M. Acute Lymphoblastic Leukemia. Hemat. Oncol. Clin. v. 23, p. 655-674, 2009.

[8] PEZZINI, T.J. CASTRO, F.S. Alterações hematológicas na leucemia linfoide aguda (LLA). Rev. Estudos, Goiânia, v.41, n.4,p. 767-776, 2014.

[9] MOREIRA, L. A. BATISTA, S. C. SILVA, J. B. M. Diagnóstico de Leucemias Linfóides: uma revisão. Revista Saúde em Foco, n. 10, p. 279-287, 2018.

[10] ADDEO, R., F, et al. Glucocorticoids induce G1 arrest of lymphoblastic cells through retinoblastoma protein $\mathrm{Rb} 1$ dephosphorylation in childhood acute lymphoblastic leukemia in vivo. Cancer Biol Ther, v. 3, n. 5, p. 470-476. 2004.

[11] ALBERT, M, K, et al. Histone methyltransferases in cancer. Semin Cell Dev Biol, v. 21, n. 2, p. 209-220, 2010.

[12] BLACK, J. C., C, et al. Histone lysine methylation dynamics: establishment, regulation, and biological impact. Mol Cell, v. 48, n. 4, p. 491-507, 2012.

[13] HERZ, H. M., A, et al. SET for life: biochemical activities and biological functions of SET domain-containing proteins. Trends Biochem Sci, n. 38, v. 12, p. 621- 639, 2013. 
[14] BIANCOTTO, C., G, et al. Histone modification therapy of cancer. Adv Genet, v. 70: p. 341-386, 2010.

[15] ARGIROPOULOS, B. AND R. K. HUMPHRIES. Hox genes in hematopoiesis and leukemogenesis.Oncogene, v. 26, n. 47, p. 6766-6776, 2007.

[16] BARLESI, F., G, et al. Global histone modifications predict prognosis of resected non small-cell lung cancer. J Clin Oncol, n. 25, v. 28 p. 4358-4364, 2007.

[17] PUI, C. H., R. C, et al. Prognostic factors in the acute lymphoid and myeloid leukemias of infants. Leukemia, v. 10, n. 6, p. 952-956, 1996.

[18] BELLAMY, J, et al. Increased Efficacy of Histone Methyltransferase G9a Inhibitors Against MYCN-Amplified Neuroblastoma. Frontiers in Oncology, v. 10, n. Maio, p. 1$14,2020$.

[19] POLLACK, et al. O6-methylguanine-DNA methyltransferase expression strongly correlates with outcome in childhood malignant gliomas: results from the CCG-945 Cohort. J. Clin. Oncol., v. 24, n. 20, p. 3431-3437, 2017.

[20] SOBIAK, et al. Thiopurine methyltransferase activity in children with acute myeloid leukemia. Oncology Letters, v. 16, n. 4, p. 4699-4706, 2018.

[21] ZHANG, et al. DNA Methyltransf. in Cancer: Biology, Paradox, Aberrations, and Targeted Therapy. Cancers, v. 18, n. 8, 2020.

[22] RAHMANI, M, et al. Aberrant DNA methylation of key genes and Acute Lymphoblastic Leukemia. Biomedicine and Pharmacotherapy, v. 97, n. November 2017, p. 1493-1500, 2018.

[23] MEYER, L. K.; HERMISTON, M. L. The epigenome in pediatric acute lymphoblastic leukemia: drug resistance and therapeutic opportunities. Cancer Drug Resistance, v. 2, n. 2, p. 313-325, 2019.

[24] NAVARRETE-MENESES, M. DEL P.; PÉREZ-VERA, P. Epigenetic alterations in acute lymphoblastic leukemia. Boletin Medico del Hospital Infantil de Mexico, v. 74, n. 4, p. 243-264, 2017.

[25] BERGMANN, A. K.; CASTELlANO, G.; ALTEN, J.; et al. DNA methylation profiling of pediatric B-cell lymphoblastic leukemia with KMT2A rearrangement identifies hypomethylation at enhancer sites. Pediatric Blood and Cancer, v. 64, n. 3, p. $1-5,2017$.

Recebido em: 01/11/2021

Aprovado em: 20/11/2021

Publicado em: 03/12/2021 